\title{
A STUDY OF PATH RELATIONSHIP OF WORKPLACE STRESSORS WITH PHYSICAL AND PSYCHOLOGICAL HEALTH OF UNIVERSITY TEACHERS
}

\author{
Saghir Ahmad ${ }^{1 *}$, Ayesha Batool ${ }^{2}$, Sadaf $\mathrm{Naz}^{3}$ \\ ${ }^{1 * 3}$ Department of Education, Hazara University Mansehra, Pakistan; ${ }^{2}$ Assistant Professor, Lahore College for Women \\ University Lahore, Pakistan. \\ Email: ${ }^{1 * 3}$ saghir.edu786@gmail.com, ${ }^{2}$ drayesharana19@gmail.com
}

Article History: Received on $23^{\text {rd }}$ February 2021, Revised on $16^{\text {th }}$ March 2021, Published on $19^{\text {th }}$ March 2021

\begin{abstract}
Purpose of the study: The purpose of this study was to explore the path relationship of workplace stressors and faculty health of university teachers.

Methodology: It was a quantitative and correlational survey study in nature. Two hundred and fifty faculty members were selected as a sample of study conveniently. A self-developed questionnaire on a Likert scale was used to explore the level of association between workplace stressors and teachers' health. The validity and item consistency were measured by structural modeling. For this, four tests were applied. The Consistency values showed strong validness and highly significant consistent and reliable scales of workplace stressors and faculty health.
\end{abstract}

Main Findings: The findings of the study show that is a strong significant positive association between workplace stressors and faculty health $r=.81$. This strong correlation confirms that the health of teaching faculty is affected by workplace stressors.

Applications of this study: The study has practical implications for teachers' health and stress factors in the teaching profession. This study contributed positively to producing new knowledge in the psychology field. The university administration may pay attention to provide a stress-free atmosphere to faculty members for their good health.

Novelty/Originality of this study: The readers may come to know about workplace stressors and how stressors are associated health of teachers. The analysis was done by using SmartPLS which was used to determine the relationship between variables.

Keywords: Workplace Stressors, Physical, Psychological, Health, Teachers, Quantitative, Survey.

\section{INTRODUCTION}

The teaching profession is more stress-oriented than any other field. The teacher works under the pressure of organizational administration, parents, and society. Most of the teachers feel this profession is unpleasant and they perceive reluctance due to psychological pressure during a job. It disturbs their mental as well as physical health. Stress sets roots of different mental and physiological side effects, for example, disappointment, fractiousness, and uneasiness just as increasingly genuine psychosomatic and burdensome indications. Therefore, faculty stress puts in danger not exclusively their wellbeing and viability but also beside the performance of students is also suffered. Hence, any kind of institution cannot achieve its desired and set goals in this situation (Aftab \&Khatoon, 2012; Fisher, 2011; Kyriacou, 2001; Van Dick \& Wagner, 2001).

Teaching is considered a "sincerely burdening and conceivably disappointing" job (Lambert et al., 2006; McCarthy et al., 2006). In the present world, educators are anticipated to do numerous activities including academic and administrative each day. They are doing significantly more than educating. They are additionally demanded to cope with misbehaviors in the classrooms and make students value-oriented and socially abilities in a sound manner. Positive and negative collaborations with learners, associates, departmental executives, and guardians are regular experiences for educators (Unal, 2000).

In nowadays the strain level is increasing in the teaching profession because of the new improvement in the procedural and administrative changes in and outside of the department and classroom. The learners' needs can raise feelings of anxiety significantly higher in the educators. The outcomes of instructor stress are extensive and antagonistically influence the educators and everybody around them, most strikingly their learners (Motie, 2010).

Constant pressure triggers a scope of physical and psychological well-being side effects are more in new teachers. Physically, anxiety debilitates the resistant framework in people and builds weakness to ailment specific in the emotional well-being. Stress compounds torment and decreases physical determinations of the human physique and the educators are usually seriously influenced because of the psychological pressure and they reach to the specialist for their treatment. It may enhance the danger of endless exhaustion, coronary illness, and different infirmities. It also drains the quality of the psychological endurances. Regular indications incorporate touchiness, mind-set swings, and depletion, which may grow into misery, nervousness, and lower personal and work-life satisfaction. These side effects have been distinguished by instructors revealing high pressure (Fisher, 2011). 
The outer aspects like apathetic students, substantial work burden, and poor working environment, educators' selfviability levels have relationships with stress also. Self-viability, characterized as people's convictions about having the ability to effectively achieve a particular goal (Bandura, 1997; Bandura, 2000; Tschannen \& Hoy, 2007), affecting instructing practices, teachers' health, and learners' inspiration and accomplishment has a mutual association with anxiety in this field. Their health is disturbed due to unnecessary pressure and high-level stress (Betoret, 2006; Pajares, 2002).

\section{RATIONALE OF THE STUDY}

The teaching profession faces the highest level of stress because they have extensive contact with people mostly in unpredictable circumstances. Due to workplace stressors like workplace relationships, class size, educational change, and reforms, lower administrative support, teachers are suffering physically and mentally. Persistent stress makes teachers ill and due to bad health, they cannot perform well. Likewise in stressful conditions teachers' capability to believe in themselves and their efforts also suffers. Thus, the relationship between workplace stressors and faculty health was explored through path analysis.

\section{SIGNIFICANCE OF STUDY}

This study's outcomes are beneficial to the Education Department administration, teachers, and students. It helps to understand the different workplace stressors and their relationship with teachers' health in universities. Teachers are performing various tasks at the same time which makes their job more stressful. Stress affects the mentally and physically of teaching faculty which in turn affects their students and everyone around them. The results of this study help to know about workplace stressors and make policies to minimize the burden and level of stress. Moreover, teachers, in general, play a pivotal role in the education system as well as in the community, due to their bad health students, department, and society suffers. Education Department needs to control stress factors to improve the quality of education and creating a good environment for teaching and learning. It helps in understanding the stressors, improving the quality of education and the universities' environment.

\section{RESEARCH OBJECTIVES}

The following objectives were measured:

1. Explore path relationship of workplace stressors with physical and psychological health of university teachers.

2. To explore the latent variable correlations between workplace stressors and faculty health of university teachers.

3. To check the $\mathrm{R}$ square value of faculty health.

4. To check the construct reliability and validity of workplace stressors and faculty health scales.

5. To check the discriminant validity of workplace stressors and faculty health scales.

6. To explore the bootstrapping path coefficients and histogram of workplace stressors and faculty health of university teachers.

\section{LITERATURE REVIEW}

Teachers have social public relations and contact with individuals more than any other field, frequently in unpredictable conditions. Numerous elements can subsidize to, and sway upon, educators' degrees of stress. These elements can be part into three general classifications: Intrinsic elements, work environment connections, and departmental culture (Skaalvik \& Skaalvik, 2016).

Intrinsic elements are related to the substance of the job for example work and time burden, discipline maintenance in class, class size, the pace of instructive change and innovation, basic leadership control and decision-making authority, physical job environment, professional freedom, and track. It is simply impractical to get ready for all circumstances to perform all activities in the class. This profession demands work in and outside the class. This is one of the causes that make this field different and stressful from other jobs (Klassen \& Chiu, 2011).

Workplace association incorporates faculty members or job fellows, guardians, and authoritative staff. Several educators complain work burden in the field of teaching separates them from others as there is almost no time for important commitment with associates. They depend on their regulatory group to give them the assets and bolster important to satisfy and complete their job duties and commitments. With constrained conditions and a lot of requests and obligations, the portion of assets can cause strife between teachers and management. A healthy departmental culture needs good communication between all faculty individuals that is fundamental to strong collegial connections with each other in the profession (Toloei et al., 2006).

Institutional culture incorporates general sentiment of the working environment, helpful and steady, positive and comprehensive administration style with a group culture or requesting and basic administration style with a dictatorial feel. Working environment connections and departmental culture can either be wellsprings of work environment stress or protects against it. Positive and strong associations with staff and an institutional culture esteeming open 
correspondence, comprehensive basic leadership, and discussion can give pressure cushions in the working environment; including additional quality and bolster structures to the figurative pressure conduit (Brackett et al., 2010).

It is progressively normal to hear educators state that their job burden has turned out to be difficultly manageable. Work burden escalation is said to bring about instructors investing less energy pondering and refining aptitudes and skills, a reduction in the thought and appropriation of non-commanded developments, and fewer expert connections with partners. This can create in instructors a sentiment of working over-burden, regularly negatively affecting class associations and student accomplishment and leaving a few educators with a sentiment of professional ineptitude (Betoret, 2006).

The impression of an essentially expanded work burden has brought about more intensity of anxiety for teaching staff. The quantity of time that must be dedicated to arranging for the teaching day: getting ready and resourcing exercises; taking care of managerial duties; developing, checking, and covering evaluation undertakings, when enhancing teaching time, leaves numerous educators with a brief period to unwind and take care of their private lives. Teachers' job life and well-being may put burden and stress on them (Olson \& Ramirez, 2015).

The climate and environment of institutions depend upon leadership and its management. A comprehensive and strong managerial group who are preferred and regarded by the university network can make for a positive atmosphere. Teachers refer to the authoritative group as a persuasive element in staff spirit. The authoritative group can be a wellspring of help; however, can have all the earmarks of being the instigator of undesirable changes and change. Teachers perceive unsupported by their organization group because of an absence of clear understanding (Betoret, 2006).

Teachers play an imperative job in the institution. They perform teaching activities as well as administrative obligations, conducting the census, and participate in polio campaigns. They are perceived as a source of inspiration and motivation. But for this, they need to behave and act mentally positive and strong, and stress-free. Those who are poor psychologically and unhealthy, are unable to maintain discipline in the class and cannot deal with students appropriately and due to this learners' performance may endure (Chaplain, 2008). Stress disturbs the psychological and physical wellbeing of teachers. High-level pressure may enhance the danger of perpetual weakness and tiredness, heart illness, and many other infirmities. It additionally exhausts mental strengths. Basic manifestations incorporate fractiousness, state of mind swings, and weariness, which may grow into sorrow, uneasiness, and lower personal and job life satisfaction. These indications have been recognized by instructors revealing high pressure and stress environment (Collie et al., 2012; Fisher, 2011).

Mental and psychosomatic sicknesses are more typical in teaching staff than non-teaching personnel. They claim weariness, exhaustion, cerebral pain, and strain. The most widely recognized self-revealed analysis among instructors are scattered of the musculoskeletal and the cardiovascular system. Because of stress they are continually whining about headaches and lower focus on the job because of stress and ailment. The psychologically poor staff has a diminished capacity to instruct and in this manner, their physical body is also disturbed. Their absence from the job disturbs the progression of guidance and association with students. Stress forces some individuals to quit this profession due to poor mental and physical health. However, this situation is problematic for this profession, academic institutions, students, and society (Van Dick \& Wagner, 2001).

The study determines the correlation between teachers' work stressors and psychological wellness (burdensome side effects, burnout, and mental issues, for example, melancholy). They are presented day by day to work stressors that have been connected to unfavorable psychological well-being impacts. The findings demonstrate that when contrasted with individuals from different peoples, instructors experience higher paces of mental issues. Teachers are at higher danger for openness to work environment brutality, with its antagonistic psychological wellness outcomes. The study has connected teaching associated stressors to burdensome and psychosomatic side effects, and also burnout (Schonfeld et al., 2017).

Job pressure is portrayed as a physiological and mental response to the destructive parts of the work environment. The present proof demonstrates that the teaching profession is exceptionally unpleasant. However, the study filled the gap in this regard. The predominance of job pressure was high. Moreover, higher accentuation is needed on work interest and work control to overcome the issue of job stress elements. Consequently, different reasons for job stress, like working conditions should be part of the study (Kabito et al., 2020).

Based on the literature available following null hypothesis has been formulated -

$\mathrm{H}_{01}$ :There is no path relationship of workplace stressors with the physical and psychological health of university teachers.

$\mathrm{H}_{02}$ : There is no latent variable correlation between workplace stressors and faculty health of university teachers.

$\mathrm{H}_{03}$ : There is no construct reliability and validity of workplace stressors and faculty health scales.

$\mathrm{H}_{04}$ : There is no discriminant validity of workplace stressors and faculty health scales. 
$\mathrm{H}_{05}$ : There is no bootstrapping path coefficients and histogram of workplace stressors and faculty health of university teachers.

\section{METHODOLOGY}

The study was conducted to follow the following method section.

\section{RESEARCH DESIGN}

The adequacy of the study relies on its procedure, wherein the researcher depicts a detailed strategy and methodology. It was a survey study based on a quantitative correlational design.

\section{POPULATION AND SAMPLING}

The population of the study was university teachers of public sectors. The convenient technique was used for selecting a sample of 250 teachers.

\section{ASSESSMENT MEASURES}

Questionnaires were developed regarding workplace stressors and faculty health on a five-point Likert scale to collect relevant information from participants. Questionnaires regarding workplace stressors and faculty health consisted of twenty-three statements. The value of the instrument is made by specialists' approval. Subsequently, the instrument was approved by field specialists. The pilot testing ensured reliability. It was guaranteed to affirm the interior consistency of items.

\section{ETHICAL CONSIDERATIONS}

Researchers conducted this study to keep in mind the ethical considerations. Permission was taken from the head of the departments and then participants were approached. They were briefed about the study, its nature, and its purpose. It was assured to respondents that data would be used only for research purposes. Their identity would not be disclosed.

\section{DATA COLLECTION PROCEDURE}

The data were distributed to 250 teachers and instructions were given on how to fill the questionnaire. After that scoring was done to get the data. The Smart PLS was used for structural analysis. The $r$-value determined the association between two constructs. Path average variance extracted, constructs validity, and reliability were checked. Detail of analysis is under following.

\section{RESULTS/FINDINGS}

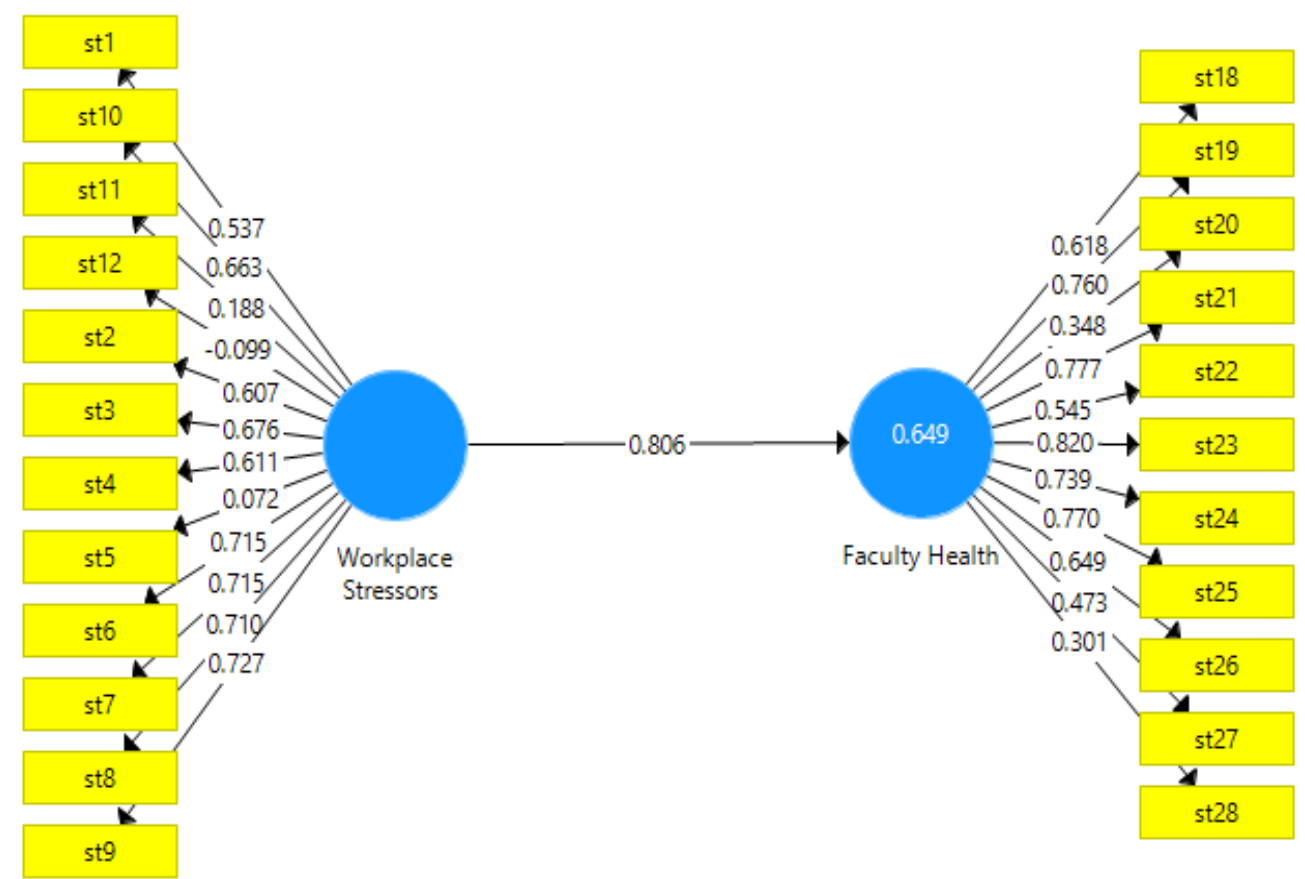

Figure 1: Items Loading and Path Relationship between Workplace Stressors and Faculty Health

\section{Source: Authors}

The above figure shows the path relationship between workplace stressors and faculty health of university teachers. Both variables contained twenty-three statements. The workplace stressors and faculty health had a strong relationship $r=$ .081 of teachers. It endorses that the health of teaching faculty is affected by workplace stressors. 


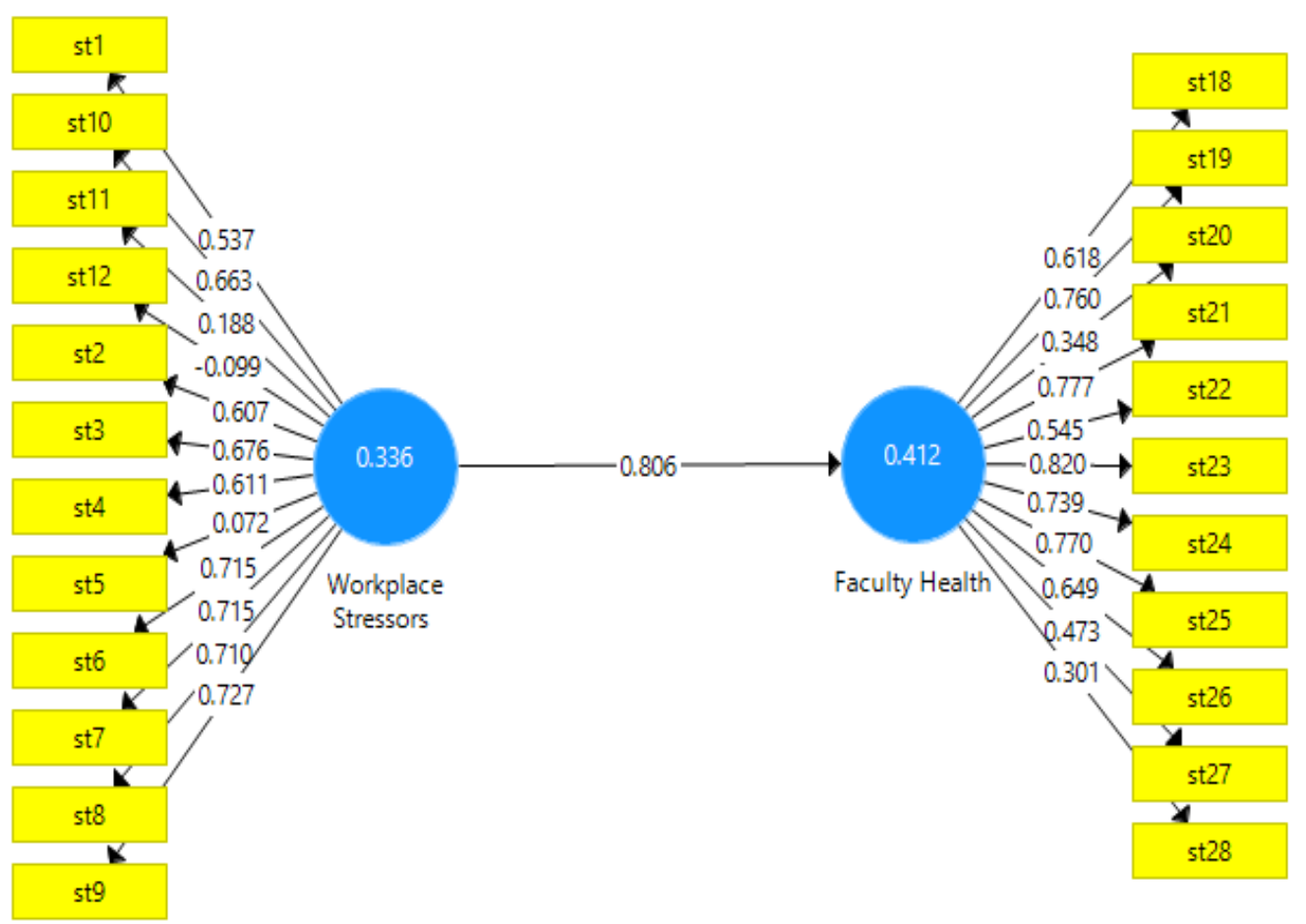

Figure 2: Items Loading and Path Average Relationship

Source: Authors

This figure contains the average variance path association between workplace stressors and faculty health. Faculty health is influenced by the unhealthy environment of the workstation. Both variables are strongly interrelated positively. If teaching staff has a good and stressless environment then their health is good and they achieve targets successfully and efficiently.

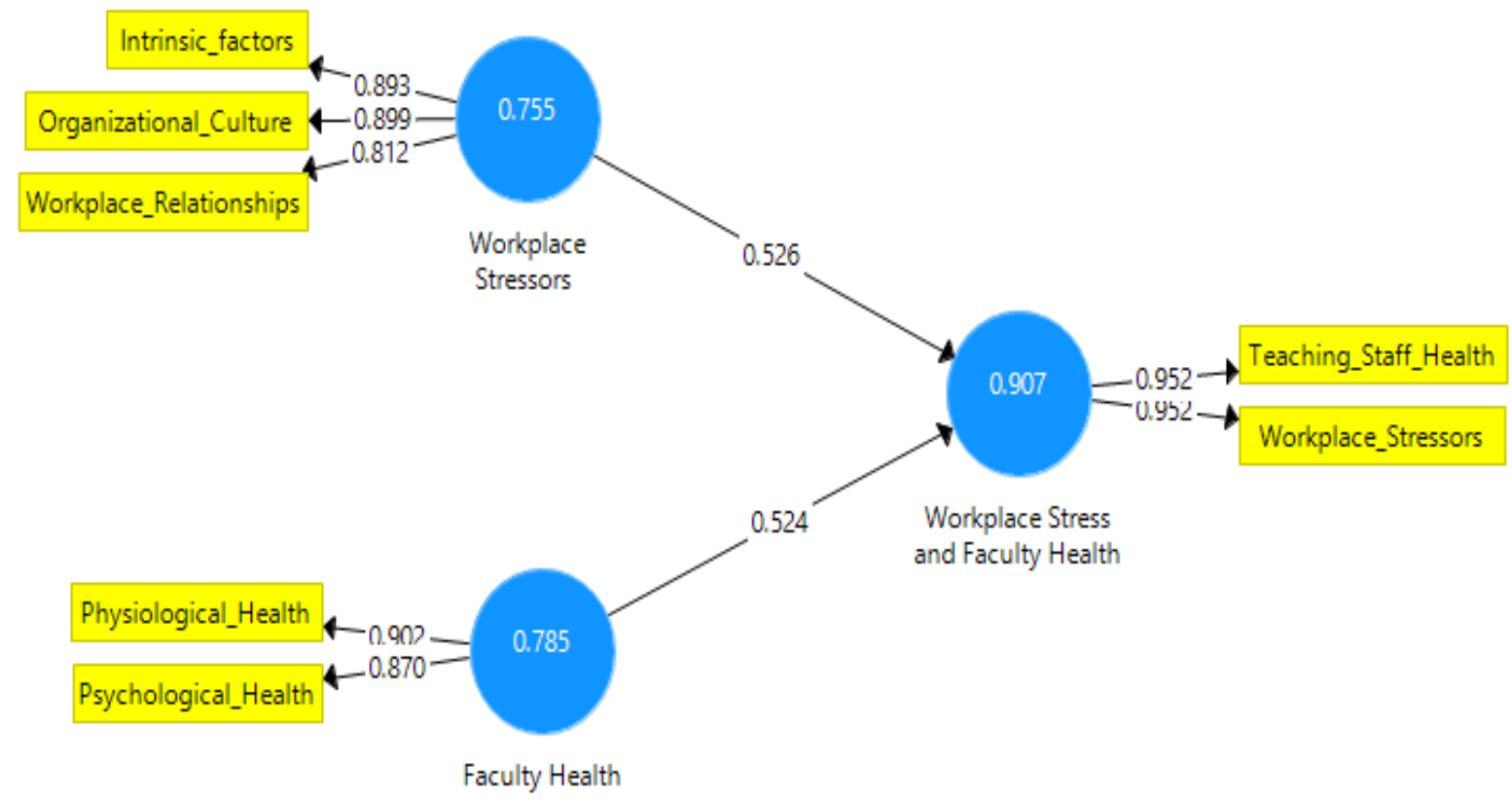

Figure 3: Path Average Relationship of Computed Factors

Source: Authors

The above figure shows the factors in blue boxes along with sub-dimensions in yellow color. It indicates that both factors stress and staff health has a moderate association with cumulative or computed variables. 


\section{Outer Loadings}

\begin{tabular}{|c|c|c|c|}
\hline \multicolumn{4}{|l|}{ Matrix } \\
\hline & Faculty Health & Workplace Stress and Faculty Health & Workplace Stressors \\
\hline Intrinsic_factors & & & 0.893 \\
\hline Organizational_Culture & & & 0.899 \\
\hline Physiological_Health & 0.902 & & \\
\hline Psychological_Health & 0.870 & & \\
\hline Teaching_Staff_Health & & 0.952 & \\
\hline Workplace_Relationships & & & 0.812 \\
\hline Workplace_Stressors & & 0.952 & \\
\hline
\end{tabular}

Figure 4: Outer Loadings of Variables

Source: Authors

This figure shows the outer loading of sub-dimensions of factors. It is the part and output of structural equation modeling in path analysis. All dimensions had values in green color, which means that all sub-factors are standard to develop structural equation modeling between workplace stressors and faculty health.

\section{Latent Variable}

\begin{tabular}{|c|c|c|c|c|c|}
\hline \multirow[t]{2}{*}{ 同 Latent Variable } & \multicolumn{2}{|c|}{ Latent Variable Correlations } & 眀 Latent Variable Covariances & & \\
\hline & & Faculty Health & Workplace Stress and Faculty & Health & Workplace Stressors \\
\hline Faculty Health & & 1.000 & & 0.952 & 0.816 \\
\hline Workplace Stress an & d Faculty Health & 0.952 & & 1.000 & 0.953 \\
\hline Workplace Stressors & & 0.816 & & 0.953 & 1.000 \\
\hline
\end{tabular}

Figure 5: The latent variable shows a strong substantial relationship between workplace stressors and faculty health

Source: Authors

\section{R Square}

\begin{tabular}{|c|c|c|c|}
\hline \multirow[t]{2}{*}{ Matrix } & 掉率 R Square & 掉亲 R Square Adjusted & \\
\hline & \multicolumn{2}{|r|}{ R Square } & R Square Adjusted \\
\hline \multicolumn{2}{|c|}{ Faculty Health } & 0.649 & 0.645 \\
\hline
\end{tabular}

Figure 6: R Square showing the value of faculty health

Source: Authors

The $r$ square is adequate at 0.3 (Ahmad et al., 2019). Therefore in this figure, the $\mathrm{r}$ square value of faculty health is $r=$ .649 , which is greater than the cut point. 


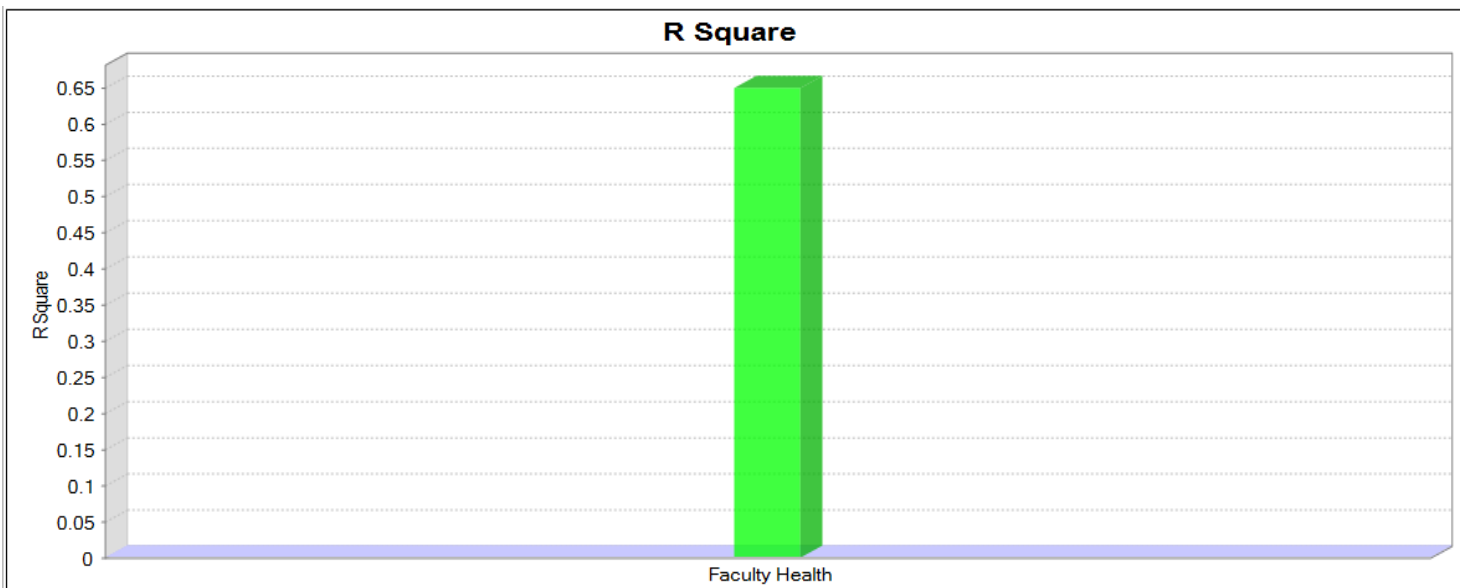

Figure 7: r square

Source: Authors

The $r$ value of faculty health in the green line is moving above 6, which is significant.

\section{Construct Reliability and Validity}

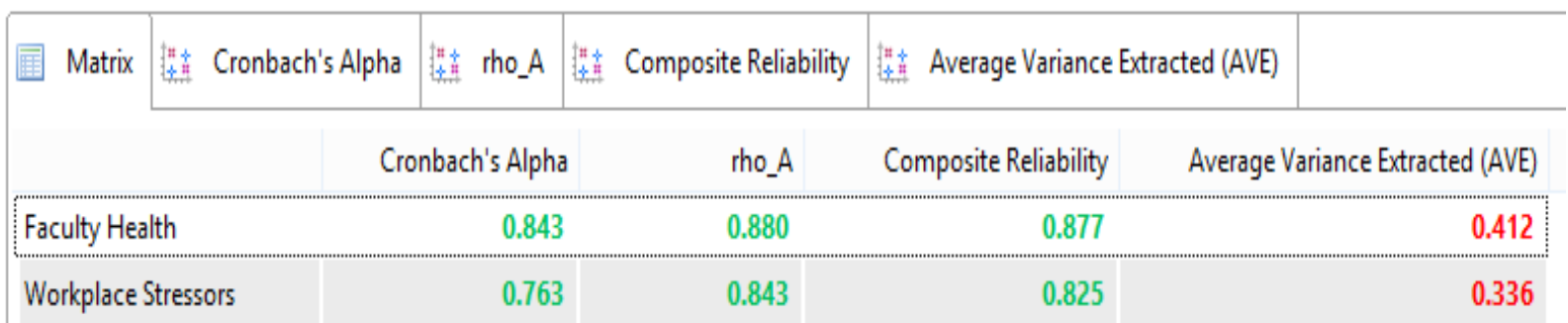

Figure 8: Reliability and Validity

\section{Source: Authors}

Ahmad et al. (2021) described scale is possibly viewed as precise and substantial when its legitimacy and dependability are affirmed. The internal consistency and legitimacy were determined by four distinct tests. The green values are indicating highly consistency of working environment stressors and personnel wellbeing. The normal difference separated qualities are not rivaling the edge. The acceptable value is .5.

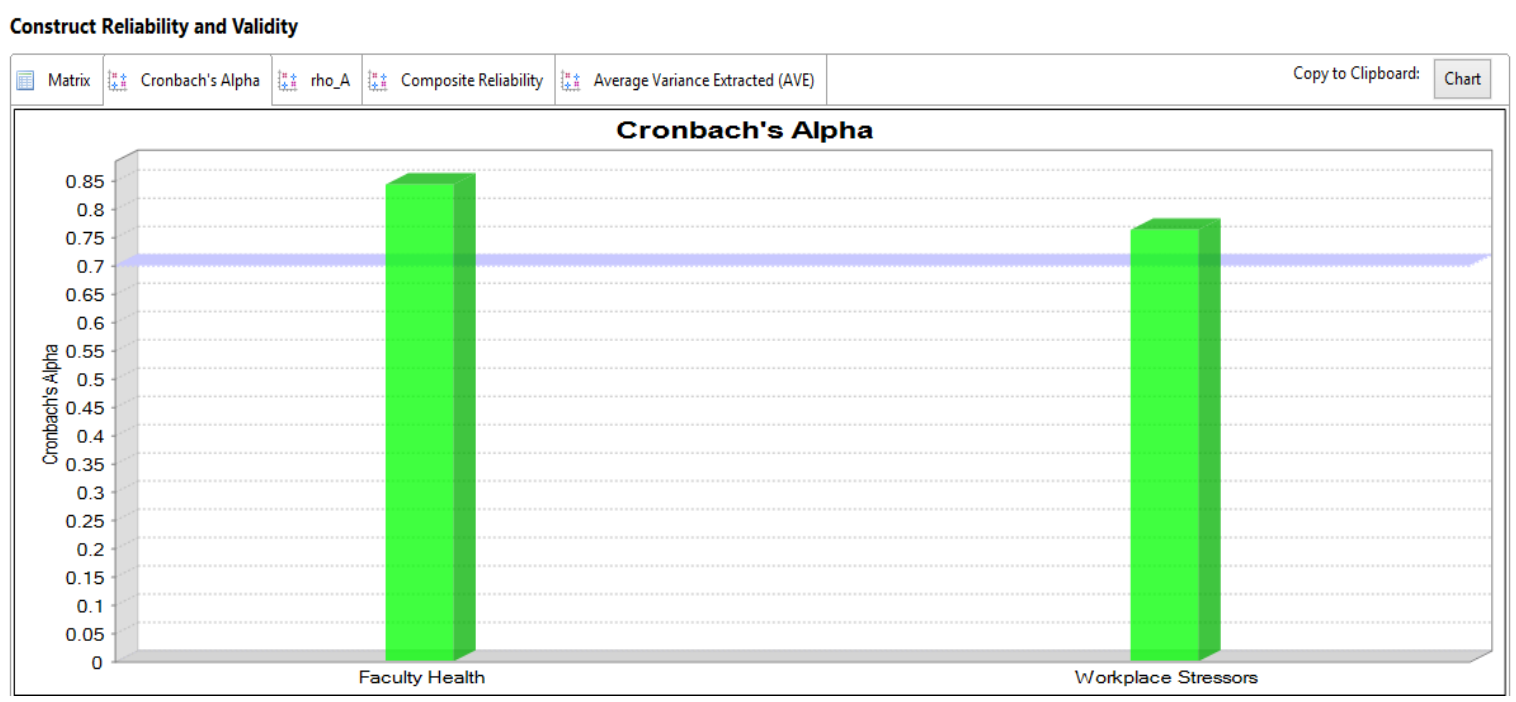

Figure 9: Cronbach's alpha

Source: Authors

The above figure is identified with Cronbach's alpha that is utilized to check the inside consistency of statements. The adequate value is at 0.7 . There are two factors in the type of green columns sowing items consistency. 
Construct Reliability and Validity

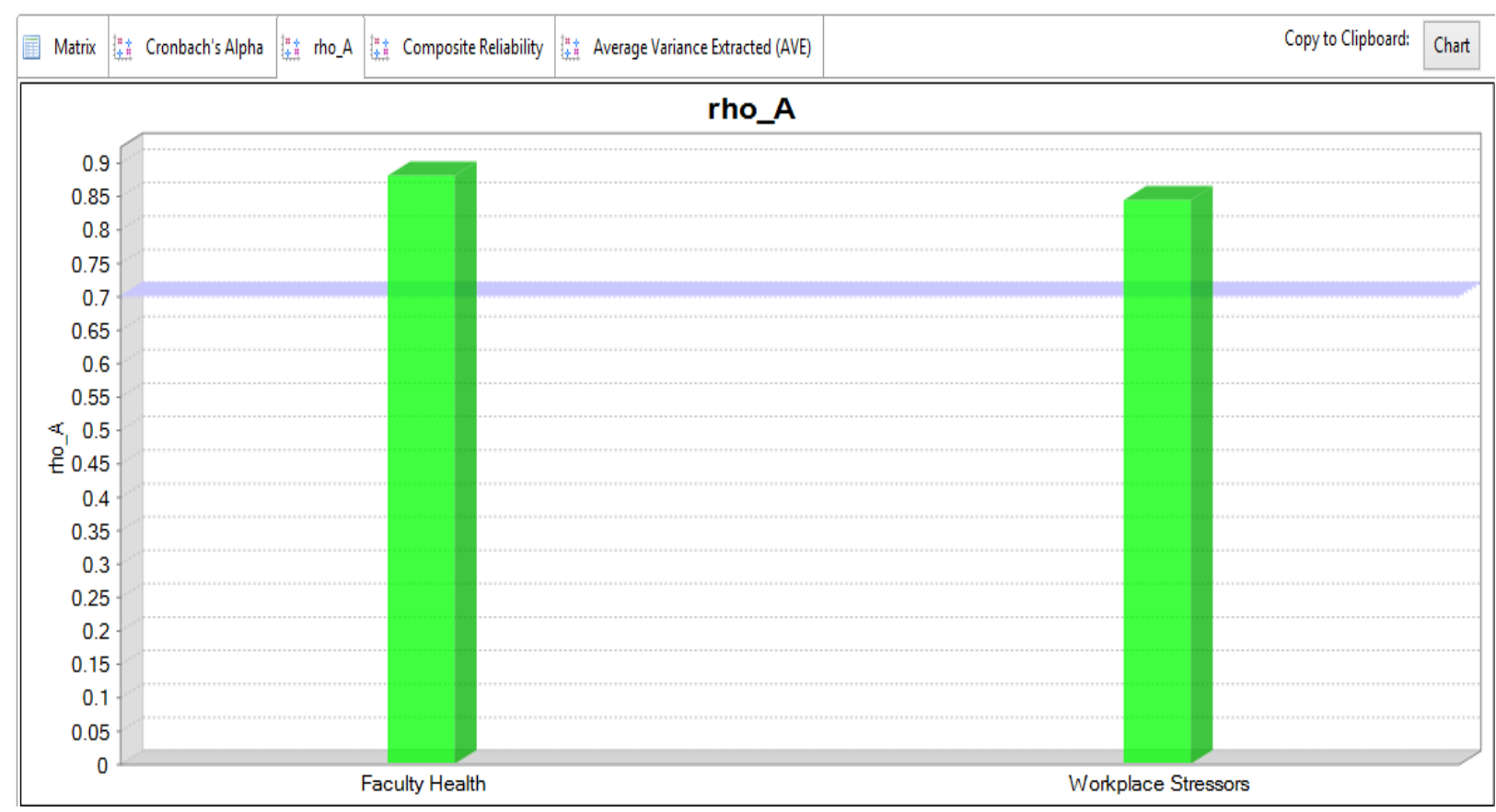

Figure 10: rho_A

Source: Authors

The above figure is identified with rho_A that is utilized to check the inside consistency of factors. The adequate value is at 0.7 . There are two factors in the type of green columns sowing items consistency.

\section{Construct Reliability and Validity}

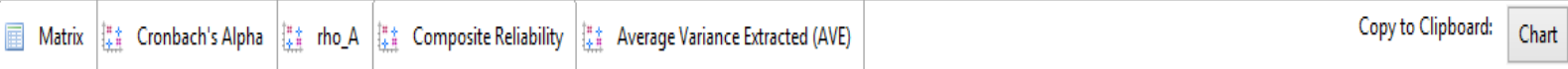

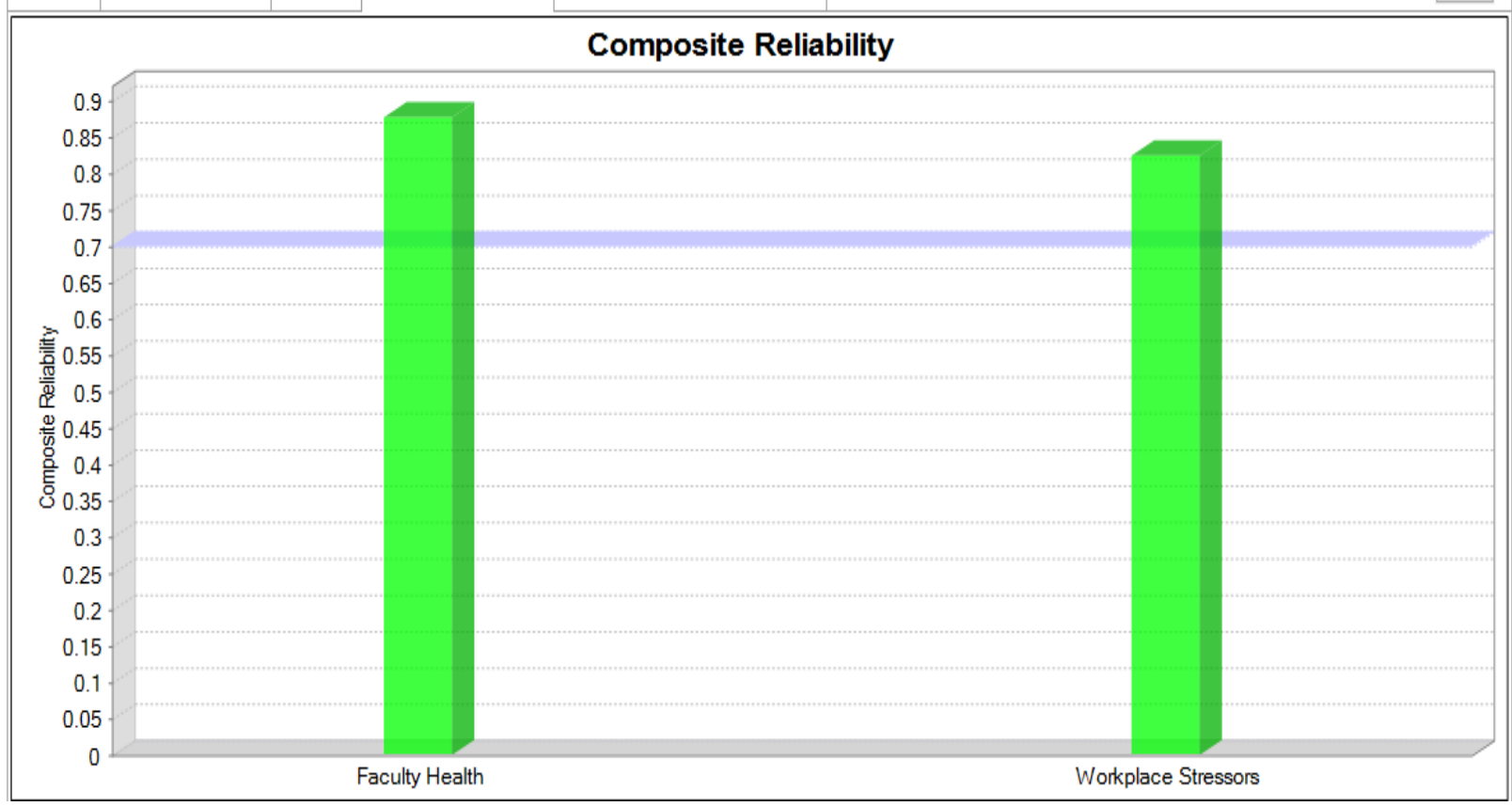

Figure 11: Composite reliability

Source: Authors

The above figure is identified with Composite reliability that is utilized to check the inside consistency of factors. The adequate value is at 0.7 . There are two factors in the type of green columns sowing items consistency. 
Discriminant Validity

\begin{tabular}{|c|c|c|c|c|c|}
\hline \multirow[t]{2}{*}{ Fornell-Larcker Criterion } & 专 c & ss Loadings & 目 & Heterotrait-Monotrait Ratio (HTMT) & 楛革 Heterotrait-Monotrait \\
\hline & & \multicolumn{2}{|c|}{ Faculty Health } & Workplace Stress and Faculty Health & Workplace Stressors \\
\hline \multicolumn{3}{|l|}{ Faculty Health } & \multicolumn{2}{|c|}{0.886} & \\
\hline \multicolumn{2}{|c|}{ Workplace Stress and Faculty Health } & \multicolumn{2}{|c|}{0.952} & \multicolumn{2}{|l|}{0.952} \\
\hline \multicolumn{2}{|l|}{ Workplace Stressors } & & 816 & 0.953 & 0.869 \\
\hline
\end{tabular}

Figure 12: Discriminant Validity

Source: Authors

Ahmad et al. (2019) considered that each factor had the greatest worth and less incentive with different factors. Essentially, staff wellbeing has greater value and it is showing least with working environment stressors. It implies scales are consistent.

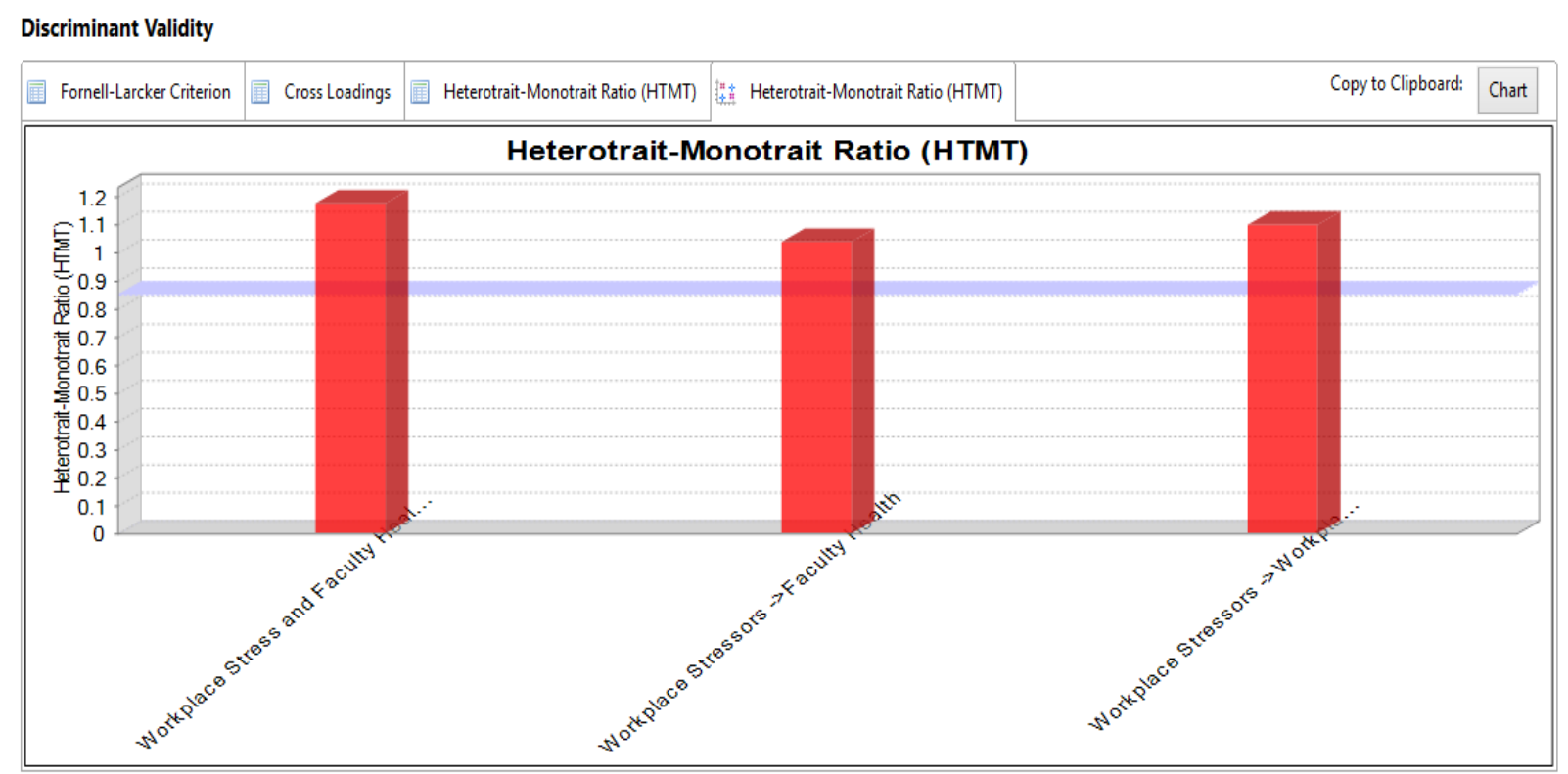

Figure 13: Discriminant Validity

Source: Authors

The above figure is identified with discriminant validity of factors. The adequate value is at 8.5 . All constructs have discrimination against others.

\section{Path Coefficients}

\begin{tabular}{|c|c|c|c|c|c|c|}
\hline \multirow[t]{2}{*}{ 同 Mean, STDEV, T-Values, P.Values } & Confidence Intervals & - Confidence Intervals Bias & rected & 同 Samples & \multicolumn{2}{|r|}{ Copyto Clip } \\
\hline & Original Sample (0 & Sample Mean (M) & \multicolumn{2}{|c|}{ Standard Deviation (STDE) } & TStatistics (0/STDEV) & PValues \\
\hline Workplace Stressors $\rightarrow$ Faculty Heath & 0.800 & 0.820 & & & 24,027 & 0,000 \\
\hline
\end{tabular}

Figure 14: Path coefficient

Source: Authors 
The above figure is related to the booth strapping path coefficient of workplace stressors and faculty health. The t-value should be above 1.96, and the p-value must below .05 in structural modeling (Ahmad et al., 2020; Ahmad \& Hussain, 2019; Hair, 2014). The $p$-value is .00, which means job stress affects the health of teaching faculty.

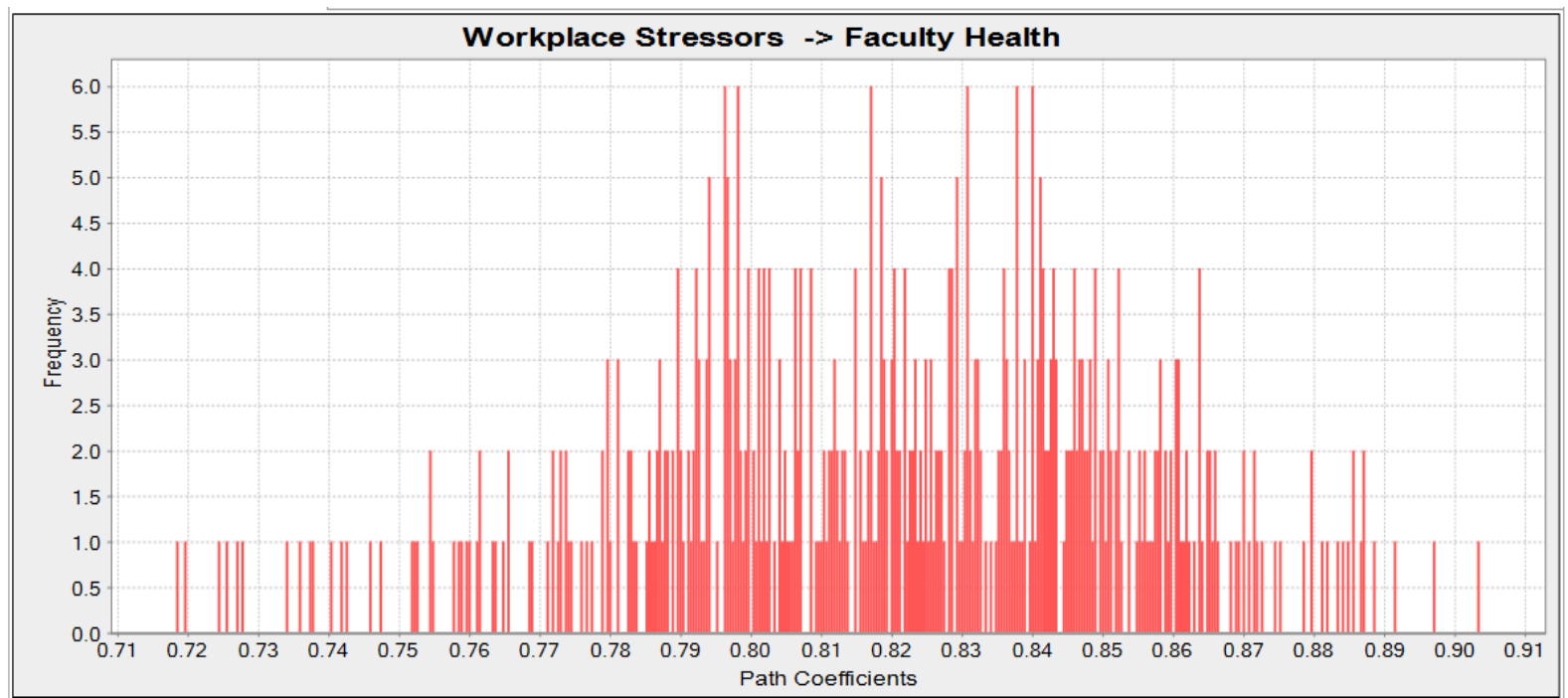

Figure 15: Histogram

Source: Authors

The histogram of workplace stressors and faculty health, which shows the range of data where it exists. Histograms for path coefficients generated by fitting group model. The value of histogram for respondents falls from 0 to 1 (Ahmad et al., 2019; James et. al, 2009).

\section{DISCUSSION}

Teaching is a challenging field. Teachers face pressure, nervousness, and various issues on a consistent schedule and these things are certifiable reasons for upsetting occasions and stress. There are different methods to reduce psychological stress and uncertain feelings by focusing on health priorities (Ahmad et al., 2020; Chirico, et al., 2020). There is a lot of work burden which teachers are facing at their job. They put their efforts and manage extra load because most universities have fewer faculty members than the required numbers. In this situation, teachers are under pressure and the work environment is full of stressful elements due to which the health of teachers is in danger. Stress disturbs the physical and psychological functions of the human body. The human mind actively performs when there is no fear and stress. The results of this study indicated that there is a strong association between stress elements in the teaching profession and the health of teachers. Stressors affect teachers' health badly. These findings are supporting previous results of different researches. The stress factors are extensive and antagonistically influence the educators' health and everybody around them, most strikingly their learners (Motie, 2010). Their health is disturbed due to unnecessary pressure and high-level stress (Betoret, 2006). Teachers play an imperative job in the institution. They perform teaching activities as well as administrative duties. Stress disturbs the psychological and physical wellbeing of teachers. Highlevel pressure may enhance different diseases (Fisher, 2011). Results are reliable of different studies although having different cultures and contexts. This thing stamps and enhances the value and worth of this study in the research field.

\section{CONCLUSION}

Teachers play an imperative job in society. They perform teaching activities as well as administrative obligations, conducting the census, and participate in polio campaigns. They are a source of inspiration and motivation. They need to become mentally positive and strong and stress-free. Those who are poor psychologically and unhealthy, are unable to perform their job functions appropriately due to anxiety and poor health. Stress distracts their mental as well as physical health. Stress sets roots of different mental and physiological side effects, for example, disappointment, fractiousness, and uneasiness just as increasingly genuine psychosomatic and burdensome indications. Persistent stress makes teachers ill and due to bad health, they cannot perform well. The purpose of this study was to develop a path relationship between workplace stressors and the health of university teachers. This study was quantitative correlation and survey type in nature. Instrumentation is considered the backbone of any study. For developing path association questionnaires were developed regarding workplace stressors and faculty health.

Path analysis was a difficult task. There was a strong significant positive association between workplace stressors and faculty health $r=.81$ of teachers. This strong correlation confirms that the health of teaching faculty is affected by workplace stressors. Both variables have a strong $r$ square and average path relationships with each other. Outer loadings of sub-dimensions of factors were measured and all were in green values which means that sub-dimensions are up to standard and valid to measure these constructs. The $r$ square value is acceptable at 0.3 . Therefore, in this study $r$ square 
value of faculty health is .65 , which is bigger than a cut point. Reliability values in green color are showing strong validness and reliable scales of workplace stressors and faculty health. Discriminant validity ensures the discrimination between variables. The cut point of discrimination is 8.5 and red lines crossed the standard point and almost touched .1 in the figure. It means the constructs in red lines have strong discrimination with other variables.

Therefore, it is concluded that path analysis confirmed the relationship of stressors which faculty members face at job station with their health. It means if there is a high-level of stressor at work then the health of the teaching staff is affected badly. But on the other side, health cannot be damaged or affected if job anxiety is controlled by academic institutions. Teachers perform their duty in a pleasant and stress-less environment. Stress damages the working capacity of the mind and an individual is unable to do something or concentrate on work. It makes instructors create different degrees of mental and physiological indications like gentle dissatisfaction, crabbiness, and uneasiness just as more genuine psychosomatic and burdensome manifestations. It also disturbs the psychologically which makes the physical body useless. Stress, pressure, and anxiety such kind of factors not just destroy the psychological thoughts of teachers as well as students, and their departments also suffer due to stressors. This study clarified categorically that teachers' health is disturbed due to workplace stressors and they cannot do their duties actively and effectively because human life is all about a psychologically strong mind and good health.

\section{LIMITATION AND STUDY FORWARD}

There are certain limitations of the study. First of all, a nonprobability sampling technique was used to draw a sample from a population. Data were collected from only university teachers. Future researchers may incorporate these kinds of limitations by taking data from school and college teachers and take a sample with the help of probability sampling techniques. These things will be helpful to consider the study more worthwhile. The suggestions section of the study demands suggestions on behalf of the findings. This study is related to the path relationship between job stressors and the health of faculty members. There is a need to reduce the workstation stressors and provide a better environment for employees. Academic institutions especially universities should overcome the anxiety from departments. This is helpful to teachers and other staff to perform well their tasks. They must be provided with a stress-free environment at the workplace for the sake of their good health. Humans cannot put their efforts a hundred percent in a pressure situation. However, heads may develop such kind of atmosphere in institutions where teaching staff feel comfortable and teaching personnel accomplish academic and administrative goals without taking any kind of pressure and anxiety. The human body depends upon good health so the administration should have very concerned with employees' health. Universities may arrange trips and academic journeys at least one time a year to give mental relaxation to teachers. There should be workshops, seminars, and conferences that how teaching faculty can control stressors or overcome them during the job. Universities should be health conscious for teachers. The university administration may take some positive initiatives to tackle and minimize the stress level at the work station. They may pay attention to provide a stress-free atmosphere to faculty members for their good health. Higher Education Commission should take innovative steps to remove stress factors from academic institutions and focus on the good health of teachers. These steps may fruitful for teachers and departments and they achieve targets successfully.

\section{IMPLICATIONS}

The findings or results of the study have practical implications for teachers' health and stress factors in the teaching profession. The results are worthwhile because instruments of job stressors and faculty health were validated in this study in our local context. Therefore, this tool is helpful for school, colleges, and university leadership to use it and measure the institutional stress elements and level of mental and physical health of faculty members. This study contributed positively to producing new knowledge in the psychology field.

\section{.AUTHORS' CONTRIBUTION}

The authors contributed to this study by performing different tasks. Dr. Saghir Ahmad Ch., presented the idea, developed objectives, and hypotheses, wrote methodology, conducted the analysis, generated diagrams/figures during analysis, wrote discussion, conclusion, and implications. He generated hyperlinks of citations with references. He also made all revisions as suggested by the Editor and External Reviewer. He also showed his interest in proofreading of paper. Dr. Ayesha Batool wrote the abstract, introduction, study rationale, and interpretation of the analysis. She also contributed to formatting. Dr. Sadaf Naz wrote literature review, significance and checked citations. Therefore, all authors contributed to this paper meaningfully.

\section{REFERENCES}

1. Aftab, M., \& Khatoon, T. (2012). Demographic differences and occupational stress of secondary school teachers. European Scientific Journal, 8(5), 159-175.

2. Ahmad, S., \& Hussain, A. (2019). Authentication of psychosomatic capability and workplace life of teachers scales by structural equation modeling. Journal of Educational Research, 22(2), 68-81. http://jer.iub.edu.pk/journals/JER-Vol-22.No-2/6.pdf 
3. Ahmad, S., Batool, A., \& Ajmal, M. (2020). Tele-Schooling as distance learning approach in schools of Pakistan during Pandemic COVID-19. International Journal of Distance Education and E-Learning, 6(1), 6682.

4. Ahmad, S., Batool, A., \& Hashmi, M. A. (2020). Relationship between spiritual practices in managing stress and teaching profession of university academicians. Hamdard Islamicus, 43(1), 77-94.

5. Ahmad, S., Batool, A., \& Hussain, A. (2019). Path relationship of time management and academic achievement of students in distance learning institutions. Pakistan Journal of Distance and Online Learning, 5(2), 191-208. http://journal.aiou.edu.pk/journal1/index.php/PJDOL/article/view/441/89

6. Ahmad, S., Batool, A., Naz, S., \& Qayyum, A. (2021). Path analysis of customer satisfaction about quality education in Pakistani universities. Elementary Education Online, 20(5), 728-743. http://ilkogretimonline.org/fulltext/218-1613099749.pdf?1614074955

7. Ahmad, S., Hussain, A., \& Batool, A. (2019). Measuring professional life quality of university teachers: Scale construction and validation. Journal of Research and Reflections in Education, 13(2), 273-281. https://ue.edu.pk/jrre/articles/Article\%2010.pdf

8. Ahmad, S., Hussain, A., \& Batool, A. (2019). Path analysis of genuine leadership and job life of teachers. Journal of Educational Sciences, 6(2), 1-14. $\quad$ https://jesar.su.edu.pk/uploa ds/journals/Article_No_01.pdf

9. Bandura, A. (1997). Self-efficacy: The exercise of control. New York.

10. Bandura, A. (2000). Cultivate self-efficacy for personal and organization effectiveness Handbook of principles of organization behaviour. Oxford, UK: Blachwell.

11. Betoret, F. D. (2006). Stressors, self-efficacy, coping resources, and burnout among secondary school teachers in Spain. Educational Psychology, 26(4), 519-539. https://doi.org/10.1080/01443410500342492

12. Brackett, M. A., Palomera, R., Mojsa-Kaja, J., Reyes, M. R., \& Salovey, P. (2010). Emotion-regulation ability, burnout, and job satisfaction among British secondary-school teachers. Psychology in the Schools, 47(4), 40617. https://doi.org/10.1002/pits.20478

13. Chaplain, R. P. (2008). Stress and psychological distress among trainee secondary teachers in England. Educational Psychology, 28(2), 195-209. https://doi.org/10.1080/01443410701491858

14. Chirico, F., Sharma, M., Zaffina, S., \& Magnavita, N. (2020). Spirituality and prayer on teacher stress and burnout in an Italian cohort: A pilot, before-after controlled study. Frontiers in Psychology, 10, 1-7. https://doi.org/10.3389/fpsyg.2019.02933

15. Collie, R. J., Shapka, J. D., \& Perry, N. E. (2012). School climate and social-emotional learning: Predicting teacher stress, job satisfaction, and teaching efficacy. Journal of Educational Psychology, 104(4), 1189-1204. https://doi.org/10.1037/a0029356

16. Fisher, M. H. (2011). Factors influencing stress, burnout, and retention of secondary teachers. Current Issues in Education, 14(1), 1-37. https://cie.asu.edu/ojs/index.php/cieatasu/article/view/658

17. Hair, J. G. (2014). A primer on partial least squares structural equation modeling (PLS-SEM). Edinburgh Gate Harlow: Pearson Education Limited. https://doi.org/10.1108/EBR-10-2013-0128

18. James, G. A., Kelley, M. E., Craddock, R. C., Holtzheimer, P. E., Dunlop, B. W., Nemeroff, C. B., \& Hu, X. P. (2009). Exploratory structural equation modeling of resting-state fMRI: applicability of group models to individual subjects. Neuro Image, 45(3), 778-787. https://doi.org/10.1016/j.neuroimage.2008.12.049

19. Kabito, G. G., Wami, S. D., Chercos, D. H., \& Mekonnen, T. H. (2020). Work-related stress and associated factors among academic staffs at the university of Gondar, Northwest Ethiopia: An institutionbased crosssectional study. Ethiopian Journal of Health Sciences, 30(2), 223-232. https://doi.org/10.4314/ejhs.v30i2.10

20. Klassen, R. M., \& Chiu, M. M. (2011). The occupational commitment and intention to quit of practicing and pre-service teachers: Influence of self-efficacy, job stress, and teaching context. Contemporary Educational Psychology, 36(2), 114-129. https://doi.org/10.1016/j.cedpsych.2011.01.002

21. Kyriacou, C. (2001). Teacher stress: Directions for future research. Educational Review, 53(1), 27-35. https://doi.org/10.1080/00131910120033628

22. Lambert, R., O’Donnell, M., Kusherman, J., \& McCarthy, C. J. (2006). Teacher stress and classroom structural characteristics in preschool settings. Understanding teacher stress in an age of accountability. Greenwich, CT: Information Age. https://webpages.uncc.edu/ rglamber/Rsch6120\%20Materials/Week\%203\%20Case\%20Stu dy.pdf

23. McCarthy, C. J., Kissen, D., Yadley, L., Wood, T., \& Lambert, R. G. (2006). Relationship of teachers' preventive coping resources to burnout symptoms. Understanding teacher stress in an age of accountability. Research on stress and coping in education. IAP - Information Age Publishing, Inc. https://doi.org/10.1037/e526412006-001

24. Motie, M. R. (2010). Prevalence of job stressors in male pre-hospital emergency technicians. Journal of Fundamentals of Mental Health, 12(1), 4-9. https://www.researchgate.net/publication/215445233_Prevalenc e_of_job_stressors in male pre-hospital emergency technicians

25. Olson, M. H., \& Ramirez, J. J. (2015). Introduction to theories of learning. Psychology Press. https://doi.org/10.4324/9781315664965 
26. Pajares F. (2002). Gender and perceived self-efficacy in self-regulated learning. Theory into Practice, 91(2), 116-125. https://doi.org/10.1207/s15430421tip4102_8

27. Schonfeld, I. S., Bianchi, R., \& Luehring-Jones, P. (2017). Consequences of job stress for the mental health of teachers. In Educator stress (pp. 55-75). Springer, Cham. https://doi.org/10.1007/978-3-319-53053-6_3

28. Skaalvik, E. M., \& Skaalvik, S. (2016). Teacher stress and teacher self-efficacy as predictors of engagement, emotional exhaustion, and motivation to leave the teaching profession. Creative Education, 7(13), 1785-1799. https://doi.org/10.4236/ce.2016.713182

29. Toloei, M., Faghihzadeh, S., \& Sadooghi-Asl, A. (2006). The nurses' motivating factors in relation to patient training. Journal of Hayat, 12(2), 43-51. http://hayat.tums.ac.ir/article-1-210-en.html

30. Tschannen, M. M., \& Hoy, A. W. (2007). The differential antecedents of self-efficacy beliefs of novice and experienced teachers. Teaching and Teacher Education, 23(6), 944-956. https://doi.org/10.1016/j.tate.2006.05.003

31. Unal, S. (2000). Professional stress of teachers, its indicators and coping attitudes. Hacettepe University Journal of Education, 19(2), 149-155. https://dergipark.org.tr/en/download/article-file/88046

32. Van Dick, R., \& Wagner, V. (2001). Stress and strain in teaching: A structural equation approach. British Journal of Educational Psychology, 71(2), 243-259. https://doi.org/10.1348/000709901158505 